\title{
NOTARIADO Y NOTARIOS EN EL MONASTERIO DE POMBEIRO
}

\author{
por \\ MANUEL LUCAS ALVAREZ
}

Los orígenes y desarrollo de la documentación notarial en Galicia han sido objeto de mi preocupación investigadora en repetidas ocasiones ${ }^{1}$.

Mi propósito en este trabajo no es ampliar la doctrina sobre el notariado en Galicia, que no ofrece por el momento novedades y que ha sido comentada ya en investigaciones anteriores ${ }^{2}$, sino completar la información documental

${ }^{1}$ M. LUCAS ALVAREZ, El notariado en Galicia hasta el año 1300. (Una aproximación), en "Notariado público y documento privado de los orígenes al siglo XIV". Actas del VII Congreso Internacional de Diplomática, Valencia 1986. Valencia, Consellería de Cultura, Educació i Ciencia, 1989, I, págs. 331-480. En esta Ponencia se recogen los trabajos realizados con anterioridad y se plantean las líneas de investigación en los dos aspectos básicos: "la doctrina notarial y su desarrollo en Galicia durante la Edad Media", "la información documental sobre notarios".

A los trabajos aquí mencionados se añaden las páginas dedicadas a este tema en la obra conjunta de M. LUCAS y Pedro LUCAS DOMINGUEZ, San Pedro de Ramirás. Un monasterio femenino en la Edad Media. Colección documental. Santiago, 1988, págs. 159173.

${ }^{2}$ Conf. aparte de los trabajos de la nota anterior, José BONO, La práctica notarial del reino de Castilla en el siglo XIII. Continuidad y renovación, en las Actas arriba mencionadas, I, pags. 159-173. Galicia sigue en todo las prácticas castellanas y de los reinos occidentales de la Península.

Para el siglo XV sigue siendo válida la monografía de Filemón ARRIBAS, Los escribanos públicos en Castilla durante el siglo XV, en Centenario de la Ley del Notariado. Sección primera. Estudios históricos, vol. I. Madrid 1964, pags. 169-260.

"CUADERNOS DE ESTUDIOS GALLEGOS", Tomo XL, Fascículo 105, Santiago 1992. 
sobre los notarios, valiéndome de una nueva colección referida al monasterio de san Vicente de Pombeiro, que se une a otras ya realizadas en parte sobre monasterios de la "Rivoira sacrata" 3.

El monasterio de Pombeiro, priorato benedictino adscrito a Cluny desde los comienzos del siglo XII, aunque anterior en sus orígenes, conserva una buena colección documental desde el siglo X al siglo XVI inicial, fecha ésta en la que se anexiona al cercano de santo Estevo de Ribas do Sil, compuesta por 287 piezas en pergamino que son, en su mayoría, documentos notariales que permiten incrementar nuestros conocimientos sobre los notarios que ejercieron su oficio en la tierra de Lemos ${ }^{4}$.

Las características de ellos en la composición de los documentos no difieren de las de otros lugares, pero, habida cuenta de las diferentes autoridades que han realizado sus nombramientos y las fórmulas y "signa" empleados para su identificación personal, considero que su enumeración y ordenación puede ser de alguna utilidad, y a ello dedico las páginas que siguen.

Según criterios ya utilizados en trabajos anteriores divido los grupos de notarios de acuerdo con la persona o autoridad que les ha promovido al oficio y de cuya auctoritas dependerá consiguientemente el notario en el ejercicio de las fides publica.

Como cuestión preliminar mostraré el derecho del monasterio a nombrar sus propios notarios. En la carta de foro que el 16 de agosto de 1398 otorga

\footnotetext{
${ }^{3}$ Conf. monografía citada en la nota 1, pags. 359-362, punto 5.4.7. "La Rivoira sacrata".

${ }^{4}$ El monasterio de Pombeiro dispone actualmente de una monografía que le ha dedicado Nicanor RIELO CARBALLO, La parroquia de san Vicente de Pombeiro. Pantón, Lugo, 1976, 47 pags. Muy sucinta en los aspectos históricos, aunque recoge con exactitud las noticias existentes hasta el momento y sus propias investigaciones, y muy amplia en la descripción del monumento. El monasterio está situado en el sur de la provincia de Lugo, municipio de Pantón, en un lugar estratégico acordonado por la confluencia de los ríos Miño y Sil. Sus dominios no fueron muy amplios y tuvieron especial incidencia los cotos del mismo Pombeiro y Beacán, junto al río Búbal, más algunas parroquias en los municipios de Pantón, o Saviñao y Monforte.

La documentación hoy conocida se conserva en tres Archivos: el Histórico Nacional de Madrid, el Histórico Provincial de Ourente, y el Catedral de la misma ciudad, que en su Sección monástica recoge la mayoría. En adelante citaremos cada uno de estos depósitos con las siglas, AHN, AHP, y AC, respectivamente, añadiendo en cada caso el número de la pieza correspondiente, y estre paréntesis el orden que ocupa en la colección diplomática en preparación, con la sigla $\mathrm{CD}$.
}

"CUADERNOS DE ESTUDIOS GALLEGOS", Tomo XL, Fascículo 105, Santiago 1992. 
el prior don Diego Fernández a unos vecinos de Beacán suscribe como notario Bernaldo Afonso, "notario por o dito prior e convento que escriui a carta por o poder de huna carta do conde don Pero". En este mismo texto se incluye la carta mencionada, de fecha 19 de diciembre de 1383, por la que el mismo prior don Diego solicita del conde de Lemos, don Pedro, que acepte la encomienda de los cotos de Pombeiro, a condición de que "nos gardedes e mantenades nosos priuylegios... Outrosy con tal condiçon... que ponamos nos o juis e notario..." Y el conde, en la aceptación de la encomienda, dice expresamente: "e damos poder que ponades juis e notario da sua mao, segundo de suso se conten" 5.

La concesión, pues, de este derecho en el caso presente está determinada por una delegación del señor temporal de la tierra; y la existencia de estos notarios monásticos demuestra que tal concesión se hizo realidad práctica.

El período del prenotariado. Igual que en otras instituciones, antes de que se dictasen las leyes y normas reguladoras de la expedición autorizada de documentos contractuales, el ejercicio de la escritura para tales contratos era una realidad a través de la intervención de scriptores o amanuenses, sin especial cualificación de auctoritas, pero que eran testigos de excepción en el sistema terstifical al uso, por su especial preparación e intervención en el hecho documentado. Suelen pertenecer a la clase monástica y sólo se recuerdan sus nombres junto al resto de los testificantes con la fórmula notuit, o scripsit. Esta etapa, que en le caso presente abarca desde el siglo $\mathrm{X}$ hasta 1281, recoge los nombres de Ariastro, Pelagius, Fernandus, Velascus, Iohannes, Petrus, I. Petri y Martinus, y un Iohan de la Cruz la escrivio ${ }^{6}$.

1.- Los notarios de nombramiento real. La designación de notarios y la concensión de la fides publica es un derecho que los monarcas han considerado siempre como parte integrante de sus obligaciones y derechos, aunque tal derecho sea delegable. El otorgante concede a su patrocinado el jercicio del notariado en una o varias zonas determinadas y el uso de un signum individualizado como marca de identificación personal. En Pombeiro

${ }^{5}$ AHP, n. 12. (CD 65).

${ }^{6}$ AHP, n. 1 y 3; AC, n. 1330 y otros. (CD 3, 6, 10, 11, 16, 18, 20, 21, 22,) Signos, S.2, S.7., S.8 y S.10.

"CUADERNOS DE ESTUDIOS GALLEGOS", Tomo XL, Fascículo 105, Santiago 1992. 
se encuentran los siguientes:

1.1. Roy Pérez. Está registrado como notario real en Chantada de Asma en otros conjuntos documentales entre 1227 y $1294^{7}$. En Pombeiro se le encuentra en un documento de 1290 relacionado con el couto de Beacán. Su intitulación dice: "Eu Roy Peres notario sobredito [de Chantada de Asma] vi esta carta que escrivio Aras Enanes en meu lugar et poge hy neu signoo en testemoyo". Este Aras Enanes será uno de los amanuenses que se recogen en el apartado 6, de los notarios sustitutos ${ }^{8}$.

1.2. Iohan Pérez de Sindrán. Sabemos que era notario por el Rey en la villa de Monforte y en la tierra de Lemos en el año 1296 y que su memoria permanece hasta 1325 en la documentación de Pombeiro. No subscribe directamente en estos documentos, sino a través de sus notarios jurados sustitutos Vivián Pérez, Fernán,Pérez y Martín Pérez. El primero dice en la subscripción: "Et eu Vivian Peres notario jurado en no couto de Poombeyro teente as veses de Iohan Peres de Sindran, notario publico del Rey en villa de Monforte et en terra de Lemos, esta carta a rogo das partes scriui et seu signal de Iohan Peres y pus que tal he". El segundo se refiere a su principal en un documento de 1304. "Et que esto seia firme et non venna en dulta rogamos Fernan Peres, teente as veses de Iohan Peres, notario publico del rey en terra de Lemos...", y más adelante: "Eu Fernan Peres per mandado de Iohan Peres notario sobredito fiz esta carta et pus en ella este signo, que es semellauel del que Iohan Peres o sobredito me dou...". Por último, Martín Pérez suscribe sus documentos entre 1323 y 1325 ocon la fórmula de notario "en o couto de Poonbeyro" en sustitución de su principal, que era "notario del rey en terra de Lemos". Todos ellos coinciden, además, en no utilizar signo propio, sino el de su notario mandante ${ }^{9}$.

1.3. Miguel Eanes. Es también notario en Lemos por el Rey. Se le menciona en una carta del año 1331, y como el anterior, delega sus funciones para el couto de Pombeiro en un sustituto. "Et que seia firme -dice el textoet non venna en dulda roganmos a Juan d'Abelles, teente as veses de Miguel Yanes notario publico do rey en terra de Lemos", y más aadelante: "Et eu Iohan d'Abelles notario sobredito a rogo do prior... esta carta... fiz escriuyr

${ }^{7}$ LUCAS, M. El notariado en Galicia, ya citado, Chantada, pag. 392, en documentos de la Catedral de Lugo y del monasterio de Oseira de AHN, AHP y AC.

${ }^{8}$ AC, n. 1529, (CD23), Signo 1.1 .

${ }^{9}$ AC, n. 1632, 1772, 1780, 1844, 2066, y AHP, n. 6. (CD 25, 26, 27, 35, 36, 37). Signo 1.2 .

"CUADERNOS DE ESTUDIOS GALLEGOS", Tomo XL, Fascículo 105, Santiago 1992. 
et este signo en ela puje, que e semellauel do de Migel Eanes notario sobredito", con lo que confirma su dependencia del notario principal ${ }^{10}$.

1.4. Alfonso González. En el año 1370 hay constancia de su presencia a través de un notario escusador. Ejercía su oficio en el couto de Pombeiro y en Val de Ferreira, como anuncia la subscripción: "Et que seia çerto mandamos... a Gomes Martins, escusasdor no couto de Pombeyro por Affonso Gonçalues, notario publico por el Rey en no dito couto et en Val de Ferreira...", y más adelante: "Et eu Affonso Gonçalues, notario sobredito, esta carta que o dito Gomes Martins escripuyo foy presente e en ela meu signo fiz en testemoio de verdade que tal he". Es la única referencia de la que hay constancia ${ }^{11}$.

1.5. Gonzalo Eanes. Según el testimonio de un documento de 1360 era notario por el rey en el couto del monasterio de santo Estevo de Ribas do Sil, y a la vez, notario por el abad y convento del monasterio, por lo que ejercía su oficio con este doble mandato. Su presencia se constata hasta 1388. "Et eu Gonçaluo Eanes -dice- notario jurado et publico en no couto do moesteiro de santo Esteuo de Riba de Sil por el Rey et polo moesteiro sobredito de santo Esteuo et abbade dese lugar, que a esto presente foy et ende scriuy duas cartas partidas per a, b, c, et en cada huna dellas puge meu nome et meu sinal, que tal he" ${ }^{12}$. Hay también noticia de que fué notario de nombramiento señorial en la tierra de Lemos, a juzgar por la suscripción de un documento de 1372 en el que se intitula "notario publico por el conde don Pedro en Val de Ferreira e en no couto de Poonbeiro", aunque aquí ejercía a través de un escusador, Gomes Martins ${ }^{13}$.

1.6. Fernán Pérez Alvelo. Era notario real en 1396 y así consta por una mención documental en la que se califica "Et eu Fernan Peres Alvelo, escribano de noso sennor el rey et seu notario publico en na sua corte et en todos los seus reynos, que a esto que sobredito he con as ditas testemuyas presente fui, et per rogo et outorgamento das ditas partes fiz escriuir esta carta et puge en ella meu signal" ${ }^{14}$.

${ }^{10} \mathrm{AC}$, n. 2199, (CD 23), Signo 1.3.

$"$ AHP, n. 7 y $8,(C D$ 45. Signo 1.4.

${ }^{12}$ AC, n. 2750, 2897, 3084, y AHP, n. 30. (CD 46, 47, 50). En el monasterio de Ribas do Sil suscribe documentos entre 1362 y 1388 (CD 82 y 98. DURO PEÑA, E., El monasterio de san Esteban de Ribas de Sil, Orense 1977, pags. 315 y 330. Signo 1.5.

${ }^{13}$ AC, n. 28907, (CD 46).

${ }^{14}$ AC, n. 3186, y AHP 10. (CD 59). Signo 1.6.

"CUADERNOS DE ESTUDIOS GALLEGOS", Tomo XL, Fascículo 105, Santiago 1992. 
1.7. Iohan Fernández de Gonte. En su doble condición de notario real y del conde don Fadrique suscribre un documento de 1418, el único del que queda referencia. "Et eu Iohan Fernandes de Gonte, notario publico en no reyno de Galiza por noso señor el Rey et en terras de Sauiñao et Sardineiros por noso señor o conde don Fadrique, a esto que dito he con as ditas testemoyas presente foy et a rogo das ditas partes esta carta en miña presença fiz escriuir et en ela mey signo fiz en testemoyo de verdade que tal he" ${ }^{15}$. Pienso que su actividad en la zona estaría determinada más bien por su nombramiento señorial que por el del Rey.

1.8. Alvaro Fernández. Es notario nombrado por los Reyes Católicos para ejercer en la ciudad de Ourense, a la vez que actúa como notario del monasterio por nombramiento del abad de santo Estevo de Ribas do Sil. Su presencia en Pombeiro está atestiguada entre los años 1486 y 1502, siempre con la suscripción: "E eu Aluaro Fernandes, escriuano del Rey e Reyna nuestros Señores e seu notario publico en a sua corte e en todos los seus reynos e señorios, e seu notario publico en na çibdad de Ourense, e notario do moesteiro e couto desanto Esteuo de Riba de Sil por lo señor abad e convento do dito moesteiro..." ${ }^{16}$.

1.9. Diego de Vilagilde. Es notario real por los Reyes Católicos, y ejerce para Pombeiro ente los años 1490 y 1492, sólo con tres referencias. La suscripción empleada es: "Eu Diego de Vilagilde escriuano de camara del Rey nuestro Señor e seu notario publico en a sua corte, en todos los seus reynos e señorios presente foy... etc." ${ }^{17}$.

1.10. Alonso de Vilabalde. Como notario al servicio de los Austrias hay una referencia en Pombeiro del año 1526; pero en Ribas do Sil es más amplia su presencia, ya que aparece con frecuencia entre 1521 y 1534 . La suscripción se expresa así: "E yo Alonso de Villabalde escribano e notario publico de sus çesareas majestades en la su corte y en todos los sus reynos e senorios en vno con los dichos testigos presente fue a lo susodicho e segund

${ }^{15} \mathrm{AC}, 3638$, (CD 86). Signo 1.7

${ }^{16} \mathrm{AC}, 5133,5134,5156,5163,5167,5198,5205,5206,5215,5238,5239,5260,5270$, 5307, 5313, 5354, 5437. (CD, 263, 264, 265, 266, 268, 269, 270, 272, 275, 277, 278, 281, 282, 283, 284. Signo. 1.8.).

En Ribas do Sil se le encuentra entre los años 1484 y 1517. Conf. DURO, E., Ribas de Sil, CD. 247, 248, 249, 250, 253, 255, 256, 257, 258, 259, 260, 261, 263, 267, 270, 271, 289, 291.), pags. 411-419 y 425.

${ }^{17}$ AC, 5211, 5228, 5280. (CD 271, 273, 280). Signo 1.9.

"CUADERNOS DE ESTUDIOS GALLEGOS", Tomo XL, Fascículo 105, Santiago 1992. 
ante mi paso aqui por mi mano lo escriui e doy fe que otro tanto queda en mi registro firmado de los susodichos, e por ende puse aqui mis nombre e syno acostumbrados, que a tal he" ${ }^{18}$.

2. Notarios de nombramiento señorial. A pesar de la nómina anterior de notarios reales, que sirvieron a Pombeiro, no se puede olvidar que este monasterio está enclavado en la tierra de Lemos y que los señores de este territorio tuvieron gran prestigio desde los primeros siglos de la Edad Media. Refiriéndome exclusivamente a los documentos de Pombeiro, recojo los notarios nombrados por los Señores de Lemos.

2.1. Fernán Pérez. Con tal nombre se cita a un escusador del notario real Juan Pérez, en 1304; y quizá sea el mismo que unos años después suscribe como "notario publico en terra de Lemos por el moy noble sennor don Alfonso, fillo del infante don Fernando". Este mismo se cita un año después con la misma cualificación y como escusador de Martín Fernández; por último en dos documentos de 1310, en uno de los cuales se dice: "notario en no ledayro de Ferreira pollo muy noble sennor don Alfonso, fillo del inffante don Felipe..." 19.

Este don Alfonso, hijo del infante don Fernando, debe ser un nieto de Alfonso X, Alfonso de la Cerda, quien efectivamente heredó de su padre el territorio de Lemos, adquirido y perdido repetidamente durante la compleja historia de los tiempos de Sancho IV y Fernando IV; pero debía conservarlo en los primeros años del siglo XIV, cuando en 1305 el infante don Felipe, hijo de Sancho IV, es enviado a Galicia para sofocar la insurreción del conde Fernán Ruiz de Castro. Derrotado éste junto al río Cabe, pasan al vencedor los territorios de aquel, pero no así la tierra de Lemos, que se incorporó más tarde al contraer matrimonio con doña Margarita de la Cerda, hija de Alfonso de la Cerda ${ }^{20}$.

${ }^{18}$ AC, 5862. (CD 287). Signo 1.10.- Conf. DURO, E., Ribas de Sil, CD 2866, 288, 293, 294, 295, 296, 297, 298, 299, 304,. 305, 306, 307, 308, 309, 310, 311, 311 a, pags. 423430.

${ }^{19}$ AHP, n. 5; AC, n. 1832, 1553-1854, 1856. (CD 29, 30, 31, 32). Signo. 2.1.

${ }^{20}$ Una síntesis de los complejos acontecimientos de la época en GONZALEZ LOPEZ, Emilio, Historia de Galicia, La Coruña, Biblioteca gallega, Serie nova, 1980, pags. 131 y ss., que resumen otra monografía del mismo autor: Grandeza y decadencia del Reino de Galicia, Ed. Citania, Buenos Aires 1957, pags. 292-309, en las que sigue esencialmente el relato de la Crónica del rey Fernando IV.

"CUADERNOS DE ESTUDIOS GALLEGOS", Tomo XL, Fascículo 105, Santiago 1992. 
2.2. Alfonso González. Hasta el año 1372 no encontramos otro notario de nombramiento señorial. Era para entonces conde de Lemos don Pedro Enríquez de Castro, sobrino de Enrique II, e hijo de su hermano don Fadrique. Este notario recibe su nombramiento del nuevo conde y asílo hace constar en la única referencia de que disponemos: "Et porque esto seja çerto e non venna en dubta rogamos e mandamos a Gonçaluo Martins, escusador en no couto de Poonbeiro por Alfonso Gonçalues notario publico por lo conde don Pedro en Val de Ferreira et no couto de Poonbeiro..." Creo que es el mismo que tiene su oficio por el monarca, aunque su signo tiene una ligera variante $^{21}$.

2.3. Ruy González I. Nombrado también por el conde don Pedro, este notario aparece ya en 1385 como "monie et notario do dito moesteiro [de Ribas de Sil] en 1385 y allí seguía en $1393^{22}$. En Pombeiro se le encuentra en 1391 como "notario jurado e apostolico en no couto de santo Esteuo de Riba de Syl polo moesteiro sobredito.. et polo abade", pero dos años después, en el mes de octubre, se califica "notario jurado e publico en no couto do moesteiro de san Viçenço de Poonbeiro polo conde don Peroe polo moesteiro sobredito e polo prior e convento do dito moesteiro"; y en tal condición sigue hasta 1398 en que desaparece su memoria ${ }^{23}$. Todavía en el año 1418 una hija suya, Aldonza Rodríguez, "filla de Roy Gonçales, notario que foy do couto de santo Esteuo de Riba de Sil" afora unas heredades que disfruta en san Xoan da Moura y que las tiene por el monasterio de Pombeiro ${ }^{24}$.

2.4. Fernán Falaco. Es el primero de los notarios que se mencionan en Pombeiro nombrados por el conde don Fadrique. La primera referencia es del año 1401 y en ella se dice: "notario publico por lo conde don Fadrique en todo o seu condado e senorio..." En Pombeiro suscribe documentos hasta 1407, y actúa también en el vecino monasterio de Ribas do Sil por los mismos años, donde suscribe documentos entre 1405 y 1406 como "escripuan e notario publico por noso senor el rey en todo o regno de Galiza e por meu

${ }^{21}$ AC n. 2897. (CD 46). Signo 2.2.- Sobre el conde don Pedro, conf. GARCIA ORO, José, La nobleza gallega en la baja Edad Media, en Liceo franciscano, nums. 97-102, (1980-1981), pags. 21-29.

${ }^{22}$ DURO, E., Ribas de Sil, CD. 96 y 100.

${ }^{23}$ AC, n. 3106, 3131, 3150, 3168, 3184, 3189, 3191, 3205, 3213; y AHP., n. 9. (CD $51,52,53,55,56,57,61,62,63,64$.) Signo 2.3 .

${ }^{24}$ AC, n. 3641. (CD 87).

"CUADERNOS DE ESTUDIOS GALLEGOS", Tomo XL, Fascículo 105, Santiago 1992. 
señor o conde don Fadrique en todo o seu condado e señorio" 25 . Este conde don Fadrique es el sucesor del conde don Pedro en Lemos y rigió sus señoríos de 1400 a 1430, recompensado también con el título de duque de Arjona ${ }^{26}$.

2.5. Pedro Afonso de Moreda. Con el patrocinio y nombramiento del conde don Fadrique ejerce su oficio Pedro Afonso de Moreda. Su primera mención corresponde al año 1412 y desaparece su memoria dos años después, en 1414. Se intitula "notario publico en no dito moesteiro et en seu conuento et en terras do Val de Ferreira por meu señor o conde don Fadrique a esto que dito he con as ditas testemoias presente foi... etc." En sus documentos pueden verse dos formas ligeramente diferentes del uso del mismo signum ${ }^{27}$.

2.6. Meén Rodríguez. Es el tercero de los notarios mencionados en Pombeiro, que lleva nombramiento por el conde don Fadrique: "notario polo conde don Fadrique en todo seu condado e señorio". La única memoria conservada es del año $1417^{28}$.

2.7. Gonzalvo Fernández. Un año antes, en 1416, suscribía como "notario publico por meu señor o conde don Fadrique en todo o seu condado e señorio" Gonzalvo Fernández, en la única referencia que de él conserva Pombeiro ${ }^{29}$.

2.8. Roy González II. Desde 1418 a 1438 en la mayoría de los documentos de Pombeiro suscribe este notario. Oficialmente figura y es "notario publico en no dito couto de Poonbeiro por meu señor o conde don Fadrique", pero debía ser, además, notario monástico en santo Estevo de Ribas do Sil, y como tal consta en un documento de 1419 , en el que se le dice "notario publico en no conuto de santo Esteuo de Riba de Sil et notario publico en no couto de Poonbeiro por meu señor o conde don Fadrique". Como tal notario de Riba do Sil está abundamente documentado en tal monasterio ${ }^{30}$.

${ }^{25}$ DURO, E., Ribas de Sil, CD 101, 102, 105, 107; y AC, n. 3284, 3307, 4142 y AHP, n. 13. (CD 66, 67, 68, 69.) Signo. 2.4.

${ }^{26}$ GARCIA ORO, José, La nobleza, pags. 29-42.

${ }^{27} \mathrm{AC}$, n. 3508, 3509, 3521, 3546. (CD 75, 76, 78, 80.) Signo 2.5.

${ }^{28} \mathrm{AC}, 3602$, (CD 84). Signo 2.6.

${ }^{29}$ AC, n. 3597. (CD 83.) Signo 2.7

${ }^{30}$ AHP,n. 14, 15, 16, 17, 18, 19, 20, 21, 22; AC, n. 3641, 3655, 3657, 3658, 3665, 3680 , $3698,3703,3736,3748,3650,3769,3787,3805,3806,3823,3840,3860-3861,3867$, $3868,3895,3904,3910,3930,3955,3961,3973,3980,3982,3985,3986,3997,4006$, 4028,. (CD 87, 88, 89, 90, 91, 92, 93, 94, 95, 96, 98, 99, 100, 103, 104, 105, 106, 107, 108,

"CUADERNOS DE ESTUDIOS GALLEGOS", Tomo XL, Fascículo 105, Santiago 1992. 
2.9. Juan Afonso de Oviedo. La muerte del duque de Arjona, don Fadrique, planteó problemas sucesorios, pero fué doña Beatriz, su hermana, la que recompuso los territorios y, a través de su matrimonio en segundas nupcias con don Pedro Alvarez Osorio, señor de Cabrera y Ribera, en el Bierzo, introdujo a la familia de los Osorio en el territorio y condado de Lemos ${ }^{31}$. Su presencia entre los notarios atestiguados en Pombeiro corresponde por vez primera a su actuación como juez en la contienda que mantienen el prior don Alfonso con la abadesa de Ferreira, por la posesión de una pesqueira. En el documento se le menciona como "señor de Cabrera y de Ribera", y el notario se considera nombrado por él "en todas las sus villas e llugares e tierras e señorios...". No tenemos nuevas menciones de este notario ${ }^{32}$.

2.10. Lope Fernández. Es notario nombrado por don Pedro Alvarez Osorio, pero dada la fecha del documento, en 1445, el notario hace constar ya su condición de señor de Monforte, además de Cabrera y Ribera, pues es por entonces cuando se instala definitivamente como conde de Lemos ${ }^{33}$.

2.11. Lopo Vázquez. Entre 1457 y 1460 suscribe un par de documentos de Pombeiro Lopo Vázquez, "notario publico en una dita vila [de Monforte] e sua jurdiçon a merçed de meu señor don Pedro Osorio, conde de Lemos, señor de Cabrera e de Ribera, e a rogo e outorgamento das ditas partes", mención en la que el notario alude al mejor señorío de su Señor y a su apellido más famoso ${ }^{34}$.

2.12. Alfonso Conde. Es el último de los notarios mencionados en Pombeiro de nombramiento señorial. Suscribe dos documentos: uno en 1461 y otro en 1472 y en ambos se intitula "notario publico en na administraçon de Val de Ferreira et couto de Poonbeiro et Eyre, et couto de Panton et de Moreda et dos Castillons, a a merçede de meu señor don Pedro Osorio, conde de Lemos, a todo esto que dito he..." En adelante no hay notarios de proce-

$110,111,112,113,114,115,116,117,118,119,120,121,122,123,124,125,126,127$, 128, 130, 131, 132.- DURO, E. , Ribas de Sil, Cd. 115, 116, 117, 118, 119, 120, 121, 122, $123,124,125,126,127,128,129,130,131,133,134,135,136,137,138,139,140,141$, $142,143,144,145,146,150,151,152,156,157,158,159,160,161,162,163,164,165$, 171, 173, 174, 175, 176, 177, 179.- Signo 2.8 .

${ }^{31}$ GARCIA ORO, J., La nobleza, pags. 43-48.

${ }^{32}$ AC, n. 3987. (CD 129). Signo 2.9.

${ }^{33}$ AC n. 4227. (CD 161). Signo 2.10.

${ }^{34}$ AHP, n. 24; AC, n. 4498. (CD 180 y 196). Signo 2.11.

"CUADERNOS DE ESTUDIOS GALLEGOS", Tomo XL, Fascículo 105, Santiago 1992. 
dencia señorial en la documentación de Pombeiro ${ }^{35}$.

\section{3.- Notarios públicos de ciudades.}

3.1. Iohan Eanes. Es el único notario que se incluye por su intervención en la sentencia arbitral dictada por los jueces Martín Domínguez y Pero Ares, de Ourense, en el pleito que mantiene don Martín Pérez, prior de Pombeiro y Gonzalo, por razón de un foro. En este documento es notario de Ourense Iohan Eanes, pero no podemos fijar su condición de notario episcopal o concejil ${ }^{36}$.

4.- Los notarios apostólicos. Forman un grupo compuesto por clérigos de la diócesis de Lugo, que actúan en diversas partes del territorio diocesano y que en Pombeiro aparecen relacionados con las varias posesiones temporales de que dispone el monasterio fuera de los lugares tradicionales. Tales notarios están nombrados por el obispo de Lugo, en virtud de la delegación pontificia de que disponen y de acuerdo con la nueva Canonística que se impuso desde mediados del siglo XII. En la documentación de Pombeiro se les encuentra sólo en el siglo XV.

4.1. Pedro Vázquez de Fionlleda. Es el más antiguo de los mencionados y su presencia se encuadra entre los años 1437 y 1447. A juzgar por el apellido toponímico debía ser natural de la zona, ya que esta feligresía está en el territorio de Lemos. Se intitula "clerigo de la diocesis de Lugo, notario publico por la autoridade apostolica". Su actuación en documentos de carácter civil puede obedecer al hecho de la jurisdicción temporal que los obispos de Lugo ejercen en parte del ámbito de su diócesis y quizá por extensión abusiva en territorios que no les corresponden temporalmente, pero que están dispuestos a admitir la fides de la auctoritas episcopal ${ }^{37}$.

4.2. Gonzalo López de Sevil. Notario apostólico como el anterior, con una sólo referencia en 1463. "Clerigo da diocesis do bispado de Lugo e notario pubrico por la abtoridade apostolical" 38 .

4.3. Roy Fernández. Es el más representado en la documentación de Pombeiro y suscribe documentos de todo tipo entre 1480 y 1482, como tal

${ }^{35}$ AC, n. 4553 y 4705 . (CD 209 y 234). Signo 2.11.

${ }^{36}$ AC, n. 2295. (CD 41.) Signo 3.1.

${ }^{37}$ AC, n. 4054, 4088, 4267. (CD 134, 148, 165.) Signo 4.1.

${ }^{38}$ AC, n. 4576. (CD 214). Signo 4.2. 
notario "por la abtoridade apostolica" ${ }^{39}$.

4.4. Gómez Ares. Igual que el anterior, mantiene una presencia permanente en la documentación entre 1482 y 1484, y puede considerarse como sucesor de aquel en la administración documental de Pombeiro. Su única titulación es la de: "clerigo da diocesis de Lugo, notario apostolico por la autoridad apostolica" 40 . Cabría pensar que cubren un vacío notarial de otros sectores en estos años.

4.5. Juan Gómez. Sólo con carácter ocasional y con motivo de propiedades sitas en las cercanías de la ciudad de Lugo suscribe este notario en documentos del año 1482. Su misma titulación, "notario publico en nos coutos do bispo por lo señor don Alfonso Enrriques e sua igleia, obispo de Lugo" indica claramente el alcance geográfico de su oficio ${ }^{41}$.

4.6. Alvaro López de Verbetoros. Lo mismo que el anterior es un notario "por la abtoridad apostolica" ocasional y sólo aparece en un documento de 1490 relacionado con posesiones de Pombeiro en las cercanías de Lugo ${ }^{42}$.

4.7. Roy Pérez. "clerigo de la diocesis de Lugo por la autoridade apostolica notario pubrico", es también ocasional y se limita su presencia a un documento de $1491^{43}$.

4.8. Pedro Méndez de Moosiños. "notario publico por la abtoridad apostolica", suscribe como tal en un foro de 1492, del casar de Outeiro, en Pantón ${ }^{44}$.

4.9. Juan de Castro. El último de los mencionados, en el período transitorio hacia la incorporación de Pombeiro a Ribas do Sil. Se le encuentra en tres documentos: uno de 1461, del que se dá traslado en 1509 y que él autoriza, y los dos restantes corresponden a los años 1506 y 1512. Suscribe como "clerigo e notario por la autoridad apostolica" ${ }^{45}$.

5.- Los notarios monásticos. La documentación de Pombeiro ha conser-

${ }^{39}$ AC, n. 4913-4914, 4954, 4956, 4957, 4958, 4960, 4961, 4965, 4995, 5004; AHP, 32; AHN, 1238/12. (CD 236, 237, 238, 241, 242, 243, 244, 245, 246, 247, 248, 249, 257.) Signo 4.3.

${ }^{40}$ AC, n. 5018, 5031, 5033, 5037, 5041, 5090; AHP 34 y 35. (CD 252, 254, 255, 256, $258,259,260,261)$. Signo 4.4 .

${ }^{41}$ AC, n. 5026. (CD 253). Signo 4.5.

${ }^{42}$ AC, n. 5231. (CD 274). Signo 4.6.

${ }^{43}$ AHP, n. 36. (CD 276). Signo 4.7.

${ }^{44}$ AHP, n. 38. (CD 279). Signo 4.8.

${ }^{45}$ AC, n. 5519, 5661, 5598. (CD 203, 285 y 287). Signo 4.9.

"CUADERNOS DE ESTUDIOS GALLEGOS", Tomo XL, Fascículo 105, Santiago 1992. 
vado la memoria de algunos de ellos en el siglo XV; en época anterior no hay referencia alguna, y parecen haber utilizado los de otras jurisdicciones, si bien, como se ha visto, algunos reunían en su persona varios nombramientos jurisdiccionales, entre ellos, el monástico.

5.1. Iohan do Castro. Es notario monástico, pero no de Pombeiro, sino del monasterio de Lousada y como tal suscribe en una composición que el prior de aquel cenobio Pedro Bidas, otorga con su tío Alfonso Alvarez, sobre bienes en esa localidad ${ }^{46}$.

5.2. Roy González, I. Ya se le ha estudiado entre los notarios de nombramiento real.

5.3. Roy González, II. Ya estudiado entre los notarios de nombramiento señorial.

5.4. Gómez Eanes de Eyré. Pertenecía a la jurisdicción del monasterio femenino de Eiré y en tal calidad suscribe el documento de 1421, como "notario publico en no dito couto por abbadesa deste lugar". Es la única referencia disponible ${ }^{47}$.

5.5. Roy García de Eyré. Seguramente originario de esta feligresía y antigo monasterio en la tierra de Lemos ejerce en Pombeiro como "notario publico en no dito couto de Poonbeiro por lo prior et convento dese lugar". Su presencia es frecuente entre los años 1433 y 1451, esporádicamente en 1466 y 1467 , con 17 testimonios aportados ${ }^{48}$.

5.6. Maestro Juan. En el año 1451 se encuentra un Maestro Juan "notario publico en o dito moesteiro e couto por o señor prior e convento", que se cita en cinco documentos de ese año, sin que se le vuelva a encontrar con posterioridad. Suponemos que sería monje y quizá con cargo en el "scriptorium" 49.

5.7. Juan da Cruz de Cerreda. Es coetáneo y sucesor del anterior, natural de esta aldea en la ribera izquierda del Sil frente a Pombeiro. Posiblemente monje del monasterio, ocupa el cargo de notario del mismo entre 1457 y 1461, con notable actividad ya que se conservan de él no menos de 31

${ }^{46}$ AHP., n. 4. (CD 24).

${ }^{47}$ AC, n. 3275. (CD 101). Signo 5.4.

${ }^{48} \mathrm{AC}$, n. 3965, 4196, 4211, 4213, 4219, 4220, 4236, 4242-4243, 4256, 4258, 4278, 4280, 4328, 4330, 4353, 4623, 4644. (CD 154, 155, 156, 157, 158, 159, 160, 162, 163, 164, $166,167,168,169,171,221,222)$. Signo 5.5.

${ }^{49}$ AC, n. 4337, 4355, 4356, 4357,. (CD 170, 172, 173, 174, 175). Signo 5.6.

"CUADERNOS DE ESTUDIOS GALLEGOS", Tomo XL, Fascículo 105, Santiago 1992. 
documentos. Se denomina "notario publico do couto de Poonbeiro por lo dito priore moesteiro".Pero ya desde 1431 tenemos noticia de su presencia, como Juan da Cruz o Juan da Cruz de Cerreda en el monasterio de Ribas do Sil, donde es primero "escusador por Roy Gonzalez de Poonbeiro" y después "notario publico del coto", hasta 1470, lo que parece dar a entender que simultaneaba su actividad entre ambos monasterios, adscrito básicamente al de Ribas do Sil ${ }^{50}$.

5.8. Alvaro Fernández de San Cosmede. Coincidiendo con el priorazgo de don Vasco ejerció la notaría del monasterio entre los años 1461 y 1469 Alvaro Fernández. Se dice: "notario publico en no couto de Poombeiro e seus terminos por don Vasco prior do dito moesteiro e monges e convento deste mêêsmo lugar". Su actividad es abundante y han quedado 22 testimonios documentales de este notario ${ }^{51}$ :

5.9. Matía López. Quizá no con la categoría de notario, pero sí adscrito al monasterio aparece este "scriptor" titulado "criado do prior", que en 1471 era don Fernando. Su esporádica actuación, reducida a un documento sólo parece indicar que fué puramente accidental ${ }^{52}$, aunque la presencia del signum puede llevar a un auténtico oficio notarial dentro del monasterio.

6. Los notarios escusadores y auxiliares. Se recogen en este último apartado los nombres de aquellos amanuenses y notarios escusadores, a los que se refiere $\mathrm{BONO}^{53}$, quien distingue entre los sustitutos del oficio y los de la persona. Las referencias que ofrecen nuestros documentos no permiten

${ }^{50}$ AHP, n. 25, 26, 27, 288; AC., n. 4408, 4418, 4428, 4442, 4454, 4455, 4456, 4461, 4462, 4463, 4465, 4467, 4482, 4483, 4484, 4493, 4494, 4503, 4508, 4509, 4524, 4525, 4527, 4528, 4529, 4530, 4531, 4532, 4533. (CD 176, 177, 178, 179, 181, 182, 183, 184, $185,186,187,188,189,190,191,192,193,194,195,197,198,199,200,201,202,203$, 204, 205, 206, 207, 208.- DURO, E., Ribas de Sil, CD 154, 160, 165, 166, 167, 168, 169 , $170,171,172,173,174,175,176,177,178,179,180,181,182,183,184,185,186,187$, $188,189,190,191,192,193,194,195,196,197,198,199,200,201,203,204,205,206$, 207, 208, 209, 210, 213, 214, 215, 216, 217, 218, 219, 220, 221, 222.- Signo 5.7.

${ }^{51}$ AHP, n. 29, 30; AC, n. 4550, 4557, 4574, 4592, 4595, 4603, 4605, 4606, 4647, 4649, $4653,4654,4657$ a), b), 4665, 4671, 4672, 4678, 4858, 4893, (CD 50, 136, 202, 210, 211 , 212, 213, 215, 216, 217, 218, 219, 220, 223, 224, 225, 226, 227, 228, 229, 230, 231, 232, 233). Signo 5.8 .

${ }_{52}$ AC, n. 4883. (CD 235). Signo 5.9.

${ }^{53}$ BONO, José, Historia del derecho notarial español. Madrid, 1982, I, 2. pags. 323 у 326.

"CUADERNOS DE ESTUDIOS GALLEGOS", Tomo XL, Fascículo 105, Santiago 1992. 
establecer con nitidez la distinción, aunque me parece que en la mayoría de los casos se refieren a los sustitutos o escusadores del officium.

De ellos el más antiguo que nos sale al paso es Aras Enanes "notario de Temes et de Villauxe en lugar de Roy Peres notario publico de Chantada d'Asma" ${ }^{4}$.

Le sigue Vivián Pérez, "notario jurado en no couto de Poonbeiro, teente as vezes de Iohan Peres Sindran, notario publico del rey en villa de Monfforte, en terra de Lemos" 55.

Y tras él, Fernán Pérez, el más interesante de todos, pues, si en un principio se muestra como "teente as veses de Iohan Perez, notario publico del Rey en terra de Lemos", y sin signo propio, como los anteriores; más tarde, en 1310 ya suscribe como notario titular: "Et que esto sea firme et non venna en dulta rogamos a Martin Fernandes, teente as vezes de Fernan Peres, notario no ledayro de Ferreira pollo muy nobre sennor don Affonso, fillo do infante don Fernando...", que parece dar a entender un ascenso y nombramiento de notario señorial con signo propio ${ }^{56}$.

En los años iniciales del siglo XIV Martín Fernández sustituye a Fernán Pérez, como se ha visto ya, y en 1325 a Iohan Pérez notario de Lemos, pero en este caso "en no couto de Poonbeyro et d'Atan" ${ }^{57}$.

En 1331 Juan de Abellés sustituye como "teente as veses de Migel Yanes, notario publico del Rey en terra de Lemos", y en 1370, Gómez Martínez consta como escusador en el couto de Pombeiro de Alfonso Gómez, notario del Rey en dicho coto y en Val de Ferreira ${ }^{58}$.

Pese a las imprecisiones, y como ya he anticipado, sospecho que debían ser en casi todos los casos notarios sustituos o escusadores del officium y no de la persona.

${ }^{54}$ AC, n. 1529. (CD 23)

${ }_{55}$ AC, n. 1632. (CD 25).

${ }^{56}$ AC, n. 1772 y 1853-1854. (CD 26, 31). Signo 6.3.

${ }^{57}$ AHP, n. 6; AC, n. 1832, 1853-1854, 1856. (CD 26, 29, 30, 31, 32, 34, 35, 36, 37).

${ }^{58}$ AC, n. 219; AHP n. 7 y 8. (CD 39, 45).

"CUADERNOS DE ESTUDIOS GALLEGOS", Tomo XL, Fascículo 105, Santiago 1992. 


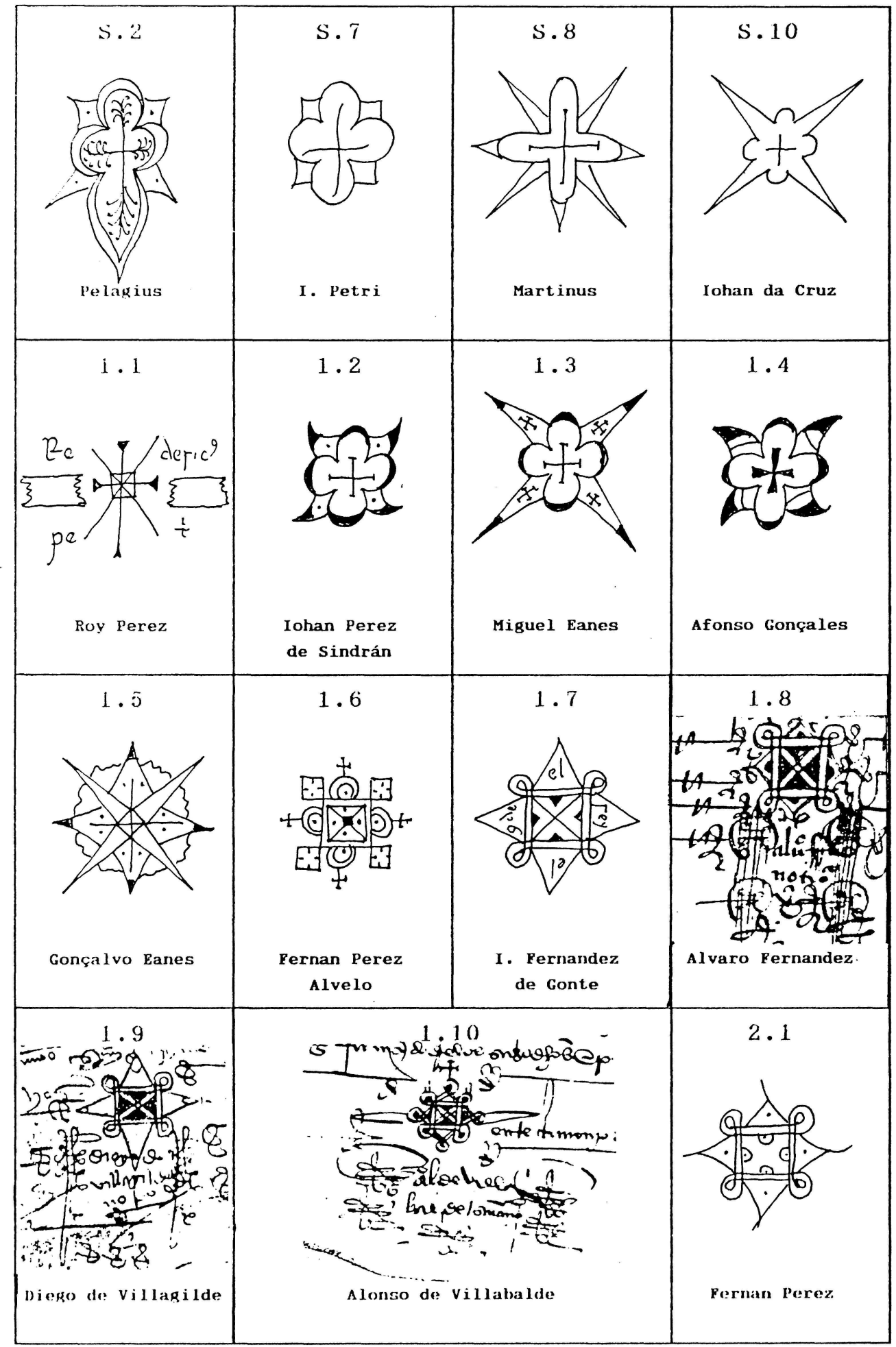

Tabla de signos notariales 


\begin{tabular}{|c|c|c|c|}
\hline Alfonso Gonzalez & Roy Gonzalez I & Fernan Falaco & Pedro Alonso \\
\hline $\begin{array}{l}\text { Pedro Afonso } \\
\text { de Moreda }\end{array}$ & Meen Rodriguez & Gonzalo Fernandez & my \\
\hline Ififojc & 2.10 & Lopo vazquez & $\psi_{\Delta}^{2.12}$ \\
\hline Iohan Yanes & Pedro Vazquez & Gonzalo & de seuil \\
\hline
\end{tabular}

Tabla de signos notariales 


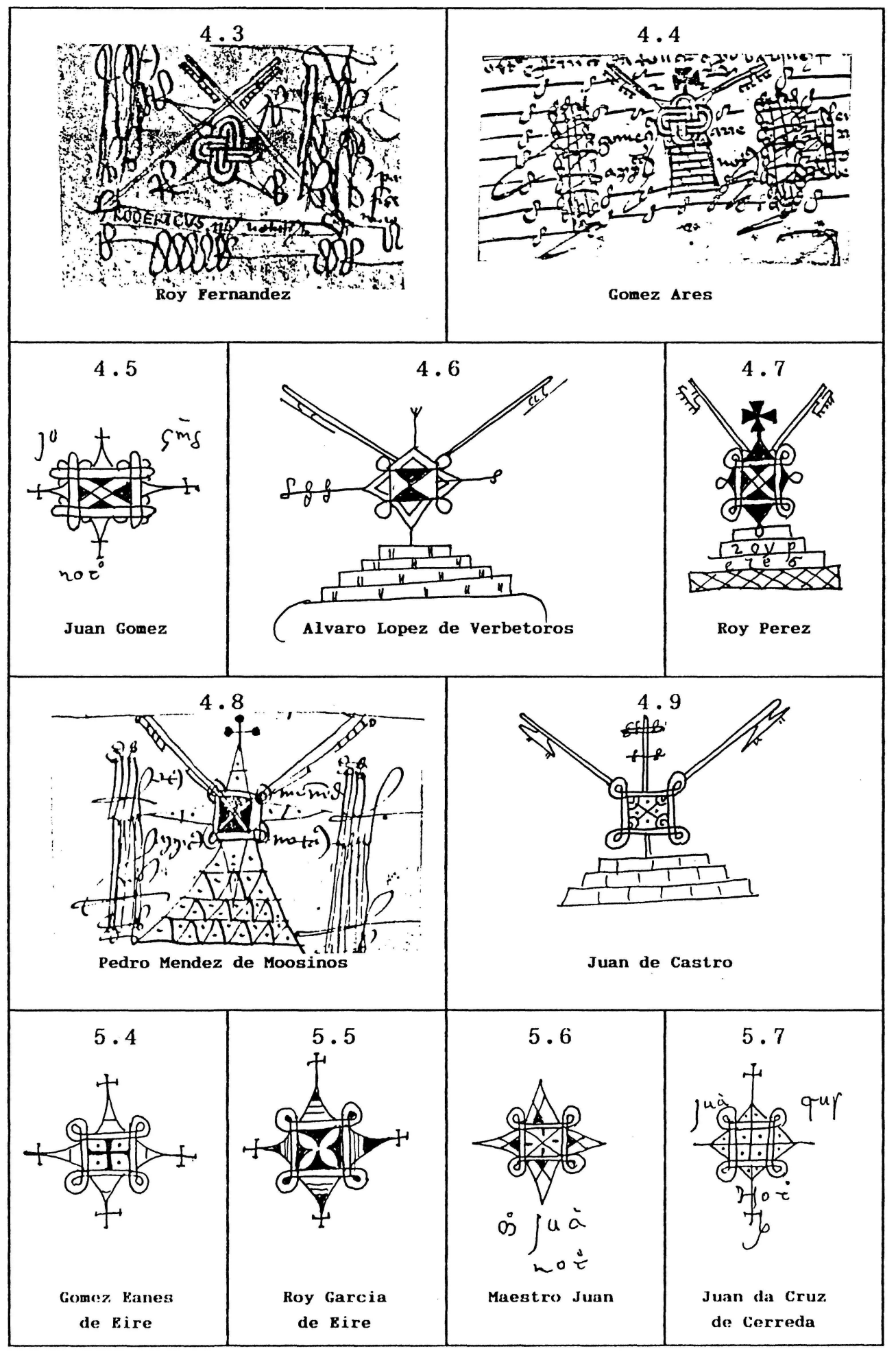

Tabla de signos notariales 


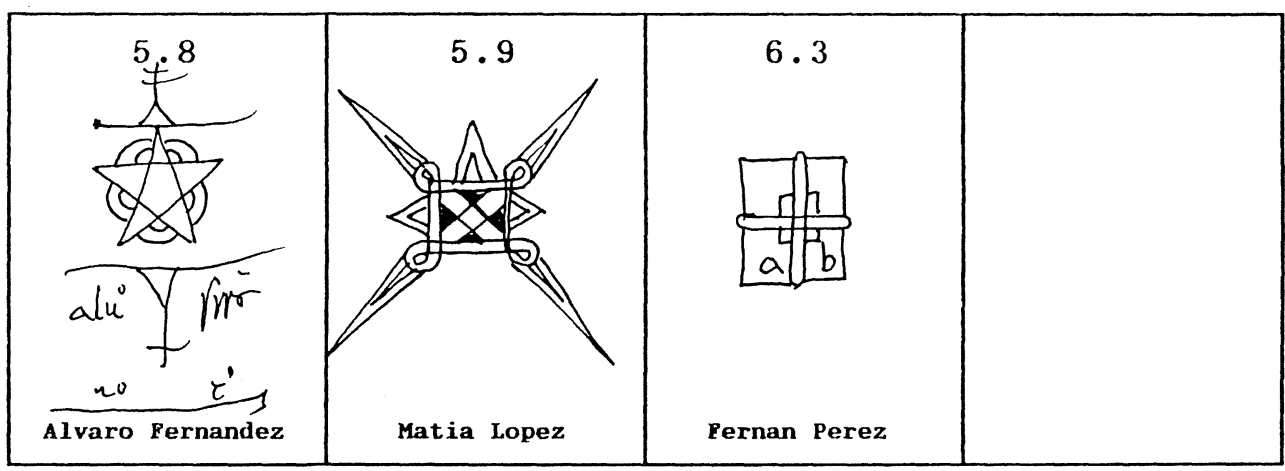

Tabla de signos notariales 